\title{
Crystal structure and band gap studies of hydrogarnet calculated results by density functional theory
}

\author{
Lijun Pan ${ }^{1,}$, Wanchao Chao ${ }^{2}$, Yan Kun ${ }^{2}$ \\ ${ }^{1}$ College of Physics and Electronic Engineering, Zhengzhou Normal University, Zhengzhou, \\ 450044, China \\ ${ }^{2}$ Zhengzhou Research Institute of CHALCO, Zhengzhou, 450041, China \\ aemail:lijunpan515@163.com
}

Keywords: Garnet; Crystal structure; Electronic properties; Density functional theory

\begin{abstract}
Herein, we investigate the hydrogarnet sample by X-ray diffraction and calculated the related garnets included grossular, katoite and hydrogrossular by density functional theory to investigate the effect of silicon composition. The results of $\mathrm{X}$-ray diffraction suggests that the chemical formula should be $\mathrm{C}_{\mathrm{a} 2.93} \mathrm{Al}_{1.97} \mathrm{Si}_{0.64} \mathrm{O}_{2.56}(\mathrm{OH})_{9.44}$. The optimized lattice parameters are in good agreement with the available data. We demonstrated the structural details of oxygen tetrahedron with or without silicon and found the stability and the band gap of garnet to be selectively modified by controlling the distribution and concentration of silicon atoms at different structural deformation levels. Moreover, the hydrogrossular configuration with the silicon atoms in separate manner is favored of the high stability and large band gap. It is firstly proposed that the band gap of hydrogarnet should be 3.17-3.65 eV by first-principles calculations. This was explained by the majority of the DOS contributions from the electrons in $\mathrm{O}$ and Ca atoms. It is believed that our research contributes to the mechanism of silicon distribution in garnet and helps the further disposal and treatment of silicate mud.
\end{abstract}

\section{Introduction}

Garnet as a common component in silicate mud belong to a cubic structure in space group Ia3d with the general formula $3 \mathrm{XO} \cdot \mathrm{Y}_{2} \mathrm{O}_{3} \cdot \mathrm{mSiO}_{2} \cdot(6-2 \mathrm{~m}) \mathrm{H}_{2} \mathrm{O}$, where the $\mathrm{X}, \mathrm{Y}$ site is occupied by divalent cation and trivalent cation, respectively. The structure of garnet may be constructed by three types of cation-oxygen polyhedron: $\mathrm{X}$ for the eight-coordinated dodecahedron, $\mathrm{Y}$ for the six-coordinated octahedron and the Si for the tetrahedron. The m varies from 0 to 3 due to the substitution of silicon-oxygen tetrahedron at different levels [1] [2]. In the past several decades, large efforts have been devoted to investigate garnets. Generally, there are katoite $\mathrm{Ca}_{3} \mathrm{Al}_{2}\left(\mathrm{O}_{4} \mathrm{H}_{4}\right)_{3}$ [1] [3] [4], grossular $\mathrm{Ca}_{3} \mathrm{Al}_{2} \mathrm{Si}_{3} \mathrm{O}_{12}$ [5-7] [9], hydrogrossular [1] [2] [ 8]. In fact, the family of hydrogrossular may extend to $\mathrm{Ca}_{3} \mathrm{Fe}_{2} \mathrm{Si}_{3} \mathrm{O}_{12}$ [9] [12], $\mathrm{Mg}_{3} \mathrm{Al}_{2} \mathrm{Si}_{3} \mathrm{O}_{12}$ [9] [12] $\mathrm{Fe}_{3} \mathrm{Al}_{2} \mathrm{Si}_{3} \mathrm{O}_{12}$ [9], $\mathrm{Mn}_{3} \mathrm{Al}_{2} \mathrm{Si}_{3} \mathrm{O}_{12}$ [9] [13] and so on if the substitution of divalent and trivalent cation is considered.

The garnet has structural deformation to some extent either by the replacement of $\left(\mathrm{SiO}_{4}\right)^{4-}$ by $\left(\mathrm{O}_{4} \mathrm{H}_{4}\right)^{4-}$ or by the substitution of divalent and trivalent cations. Start from the katoite, Lager et al. confirmed that the value of lattice parameter is about $12.5695 \AA$, which decreases as the Si atoms are introduced [2] [4], which conforms to the result [14]. On the whole, the $\mathrm{OH}$ tetrahedron may be regarded as a $\mathrm{H}$-associated point defect [2], in which the short $\mathrm{O}-\mathrm{H}$ bond from $0.65-0.74 \AA$ [2] [4] [8] or 0.93-0.96 $\AA$ [1] [7] [15] implies the disorder degree of tetrahedron. In addition, this is the similar lattice disorder case for the substitution of divalent and trivalent cations in henritermierite [16] and pyrope and grossular [17]. The electronic properties of garnet series which are influenced by the structural distortion are worth of investigating carefully [14] [18-21]. Cano et al. showed that grossular has a direct band gap of $5.22 \mathrm{eV}$ [14]. The first-principles studies may provide the reliable results in garnets, for examples, that of yttrium gallium garnet and yttrium iron garnet was determined to be $3.51 \mathrm{eV}$ [20], $2.18 \mathrm{eV}$ [21], respectively. In summary, the mentioned above 
researches based on the density functional theory have reproduced the experimental results well. Little is known about the complex structure of hydrogrossular.

In the present work, the structure and electronic properties of garnet minerals including grossular, katoite and hydrogrossular are demonstrated by a combination of first-principles calculations and experiments for the purpose of investigating the effect of $\mathrm{Si}^{4+}$. To our knowledge, no analogous calculation has been carried out. Specifically, the calculated band gap was compared with respect to the optical band gap.

\section{Method}

The samples were prepared and provided by Zhengzhou Research Institute of CHALCO. XRD measurements were carried out with $\mathrm{Cu} \mathrm{K} \alpha$ radiation, employing Bruker D8 diffractometer at 40 $\mathrm{mA}$ and $40 \mathrm{KV}$, a scan step size of $0.05^{\circ}$ and $2 \theta$ range from $3^{\circ}$ to $90^{\circ}$. We adopted herein a first-principles approach with the Vienna $a b$ initio simulation Package (VASP) [22]. Briefly, the total energies have been calculated within generalized gradient approximation (GGA) [23] and periodic boundary conditions with the energy cutoff $400 \mathrm{eV}$, with the energy and the force convergence criterion on each atom fixed to be $0.0001 \mathrm{eV}$ and $0.01 \mathrm{eV} / \AA \AA$, respectively. The number of atoms in grossular, katoite in per unit cell is 160, 232, respectively. While that of hydrogrossular is 217 or 214 which is related to the amount of Si. The calculations are checked using a $3 \times 3 \times 3$ Monkhorst-pack k-point mesh [24] to ensure a sufficient number of $\mathrm{k}$ points in the irreducible Brillouin Zone (BZ).

\section{Results and Discussion}

The X-ray power patterns of the garnet sample are shown in Fig.1. The peaks indexing confirms the sample with the stoichiometry of $\mathrm{Ca}_{2.93} \mathrm{Al}_{1.97} \mathrm{Si}_{0.64} \mathrm{O}_{2.56}(\mathrm{OH})_{9.44}$ first proposed by Sacerdoti and Passaglia [8] (ICSD-No.49772), who measured the experimental cubic cell parameter $\alpha$, the value of which is $12.38 \AA$ and established all of the $\mathrm{Ca}, \mathrm{Al}$ and $\mathrm{O}$ atomic positions with the full occupancy. However, there are about 5.1 Si atoms per unit cell. The Si atoms have uncertain positions with the occupancy of 0.214 and twenty four possible sites; we adopted two calculated hydrogrossular models with five Si atoms or six ones. Two extremes for the largest and smallest Si-Si distance between each other are computed. It may be divided into four types: five Si with the largest distance (5Si-L), five Si with the smallest distance (5Si-S), six Si with the largest distance (6Si-L) and six Si with the smallest distance (6Si-S).

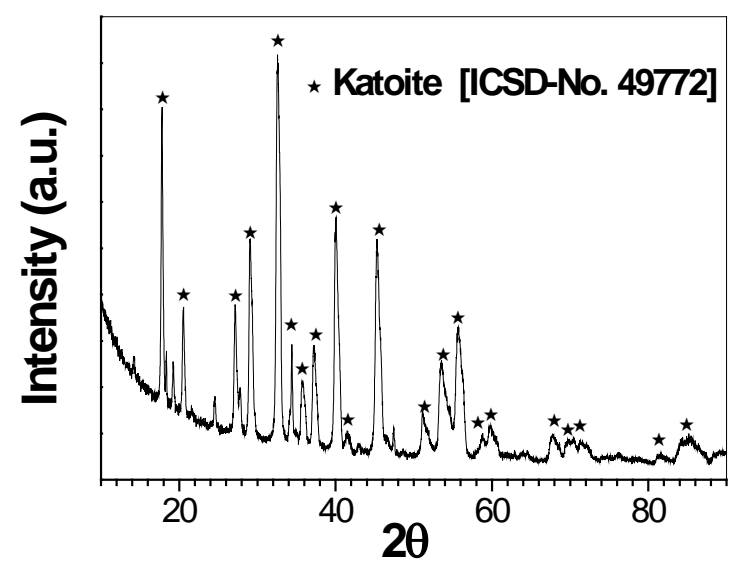

Fig. 1. X-ray power diffraction pattern of the sample, the Bragg reflex positions of $\mathrm{Ca}_{2.93} \mathrm{Al}_{1.97} \mathrm{Si}_{0.64} \mathrm{O}_{2.56}(\mathrm{OH})_{9.44}$ are marked.

The structure of grossular which contains 24 calcium, 16 aluminum, 24 silicon and 96 oxygen atoms in per unit cell is shown on the left side of Fig.2 and that of katoite is depicted on the right 
side. The transformation from katoite to grossular or hydrogrossular may be regarded as the total or partial $\left(\mathrm{SiO}_{4}\right)^{4-}$ substitution of $\left(\mathrm{O}_{4} \mathrm{H}_{4}\right)^{4-}$, the scheme of which is demonstrated in the middle of Fig.2.
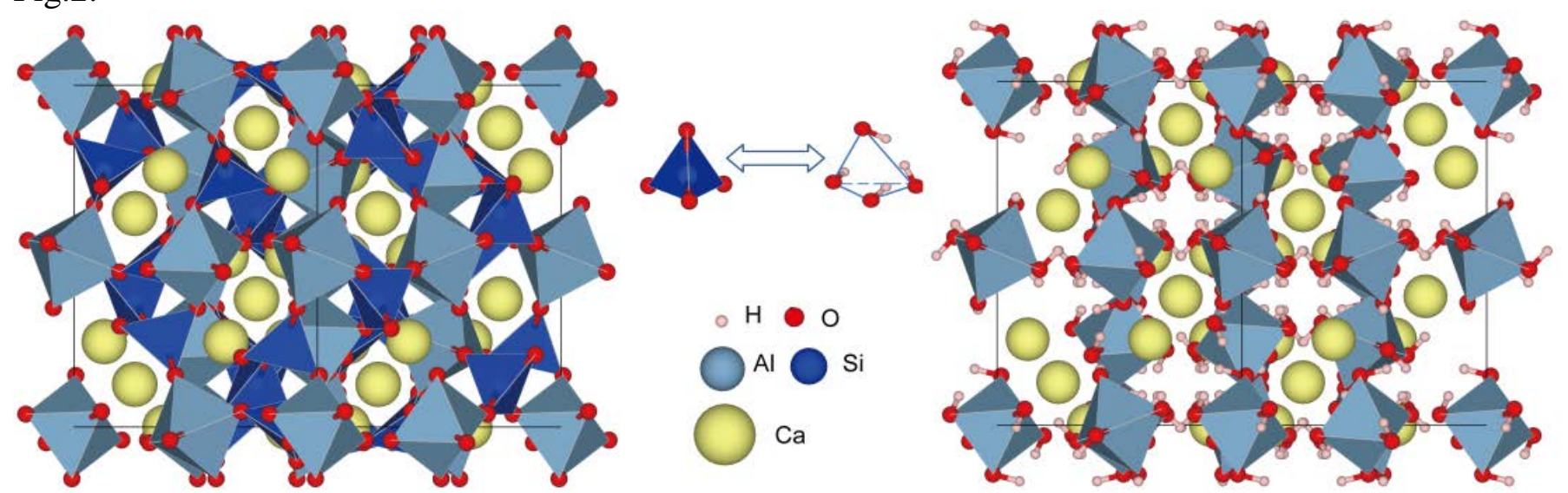

Fig.2. The side view of grossular (on the left), the scheme of $\left(\mathrm{SiO}_{4}\right)^{4-}$ substitution of $\left(\mathrm{O}_{4} \mathrm{H}_{4}\right)^{4-}$ (on the upper middle) and the side view of katoite (on the right).

The lattice parameter of grossular is consistent with the previous studies [2] [4] [7] [14], and the value of katoite is $12.38 \AA$, slightly lower but close to the results [2] [4] [7]. Both of them have lower formation energies than partial Si substituted configurations due to the higher symmetry. The stable structure is obtained as the Si atoms separate as far as possible for five and six Si cases. The $\mathrm{O}-\mathrm{H}$ bond length in our calculations has the range of 0.97-1.00 $\AA$, which approve of the studies [1] [7] [15]. It is deduced that the $\mathrm{O}-\mathrm{H}$ bond length is independent of the chemical compositions.

The optimized structure of $\left(\mathrm{O}_{4} \mathrm{H}_{4}\right)^{4-}$ tetrahedron in katoite is shown in Fig.3. There are two types of O-O distances: the values are $3.10 \AA$ and $2.89 \AA$, both of which are in good agreement with the references [2]. The atomic hydrogen distribution in previous studies [1] [2] [4] [8] [15] may be summarized as "hand in hand" manner that the hydrogen atoms extend toward each other, while, the manner of ours is regarded as the "end to end" that the hydrogen atoms are almost direct along the tetrahedral edges with the $\angle \mathrm{O}-\mathrm{O}-\mathrm{H}$ angle of $5.95^{\circ}$. It is first revealed by first-principles approach.



Fig.3. The side view of the optimized structure of $\left(\mathrm{O}_{4} \mathrm{H}_{4}\right)^{4-}$ tetrahedron in katoite.

In the following, the electronic properties of hydrogrossular were shown in Fig.4. All of them are direct gap type. The band gap of grossular is calculated to be $5.25 \mathrm{eV}$, which is identical to the calculation [14]. We found that the total density of states near the Fermi level is mainly attributed to the energy states of $\mathrm{O}$ and $\mathrm{Ca}$ atoms and the Si contribution which has little effect. It is inferred that the electrons bonded to Ca-O are relatively "active" while the electrons are restricted strongly by the Si-O bond. The gap of katoite is calculated to be $4.78 \mathrm{eV}$. It is realized that the band gap which is mainly affected by the electrons in $\mathrm{O}$ and $\mathrm{Ca}$ atoms in the valence band maximum (VBM) and conduction band minimum (CBM). It is seen that the $\mathrm{O}$ atoms and $\mathrm{Ca}$ atoms as the first and second 
contributor provide the main responsibility near the Fermi level. The band gaps of 5Si-L, 5Si-S configurations may be calculated to be $3.65 \mathrm{eV}$ and $2.94 \mathrm{eV}$, respectively. Similar, 6Si-L has a gap of $3.17 \mathrm{eV}$, larger than that of $6 \mathrm{Si}-\mathrm{S}$, the value of which is $2.92 \mathrm{eV}$. The difference which is ascribed to the decrease of conduction band minimum is aroused by Si distribution.
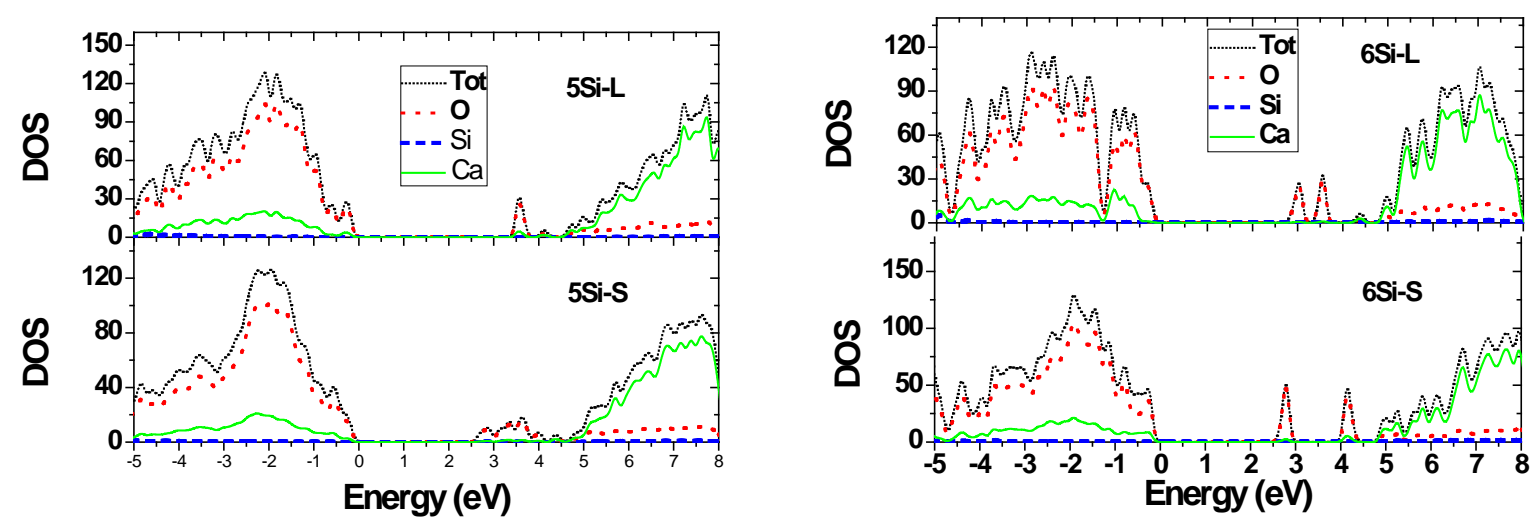

Fig. 4. The total density and partial of states of hydrogrossular for five Si atoms (Fig.6a), and six Si ones (Fig.6b).

The band gaps and CBM, VBM as functions of lattice parameters for different compounds are presented in Fig.5. The band gap and CBM of katoite are labeled by red circle. The gaps of Si substituted configuration decreases with the increasing of lattice parameter; this tendency is consistent with the curve of CBM. As shown, the variation of VBM is limited in a small scope. It may be deduced that the CBM plays a main role in the variation of band gap rather than VBM. On the whole, our calculations revealed that the Si substitution may be used to selectively modify the band gap by altering the CBM.

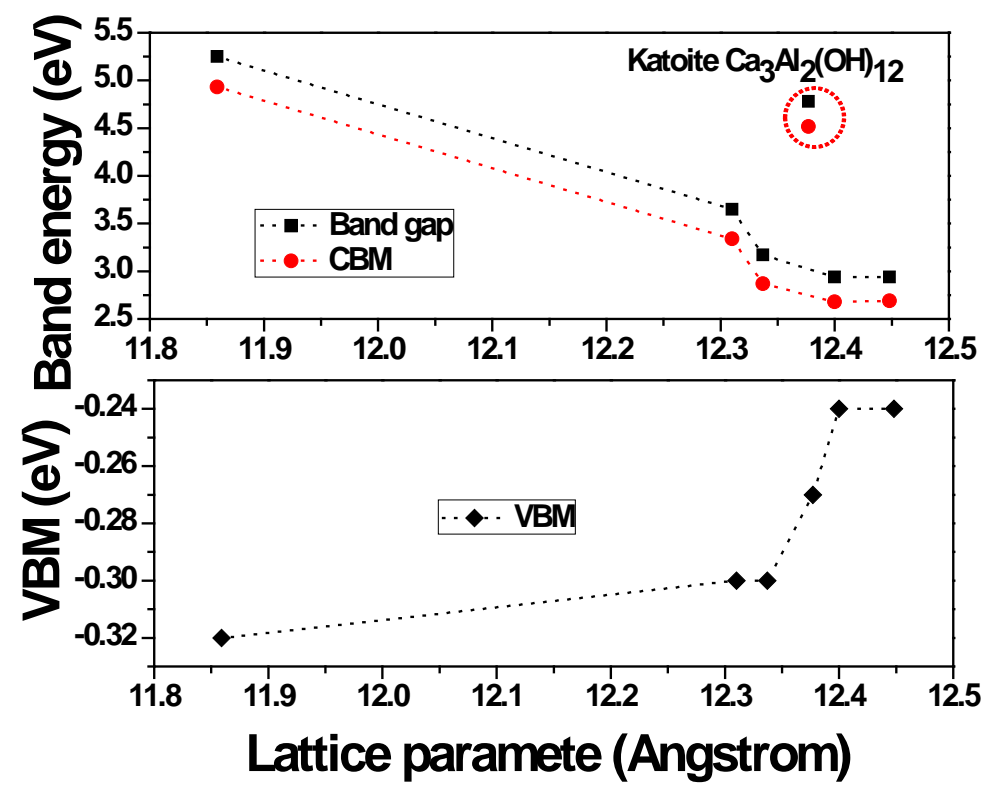

Figure 5. The band gaps and values of CBM, VBM as functions of lattice parameters for different compounds, the grossular and katoite are labeled in red circle.

\section{Conclusions}

In this paper, we have investigated the chemical compositions of hydrogrossular sample by X-ray diffraction with the stoichiometry of $\mathrm{Ca}_{2.93} \mathrm{Al}_{1.97} \mathrm{Si}_{0.64} \mathrm{O}_{2.56}(\mathrm{OH})_{9.44}$. By density functional theory, we found that $\left(\mathrm{SiO}_{4}\right)^{4-}$ tetrahedron involved of $\mathrm{Si}-\mathrm{O}$ and $\mathrm{O}-\mathrm{O}^{(1)}$ distances provide the mainly 
contribution to the distortion. The stable structure is obtained with the Si atoms separate as far as possible. The stability of configuration linearly decreases as the lattice parameter increases except the katoite. We also proposed that the hydrogen atoms in $\left(\mathrm{O}_{4} \mathrm{H}_{4}\right)^{4-}$ tetrahedron trend to "end to end" manner along the tetrahedral edges with the $\angle \mathrm{C}-\mathrm{C}-\mathrm{H}$ angle of $5.95^{\circ}$. The gaps of Si substituted configuration decreases with the increasing of lattice parameter; this tendency is consistent with the curve of CBM, which indicates that the CBM plays a main role in the variation of band gap rather than VBM. The majority of the DOS contributions come from the electrons in $\mathrm{O} 2 \mathrm{p}$ states and $\mathrm{Ca}$ 3p states. The photon band gap should be in range of $4.27 \mathrm{eV}$ to $4.75 \mathrm{eV}$ combining the results of the absorption spectra and reflectance spectra. The 5Si-L and 6Si-L configurations having the largest gap of $3.65 \mathrm{eV}$ are possible candidates considering the structural stability and energy band gap. Our calculations reveal that the Si substitution may be used to selectively modify the stability and the band gap by altering the CBM with the large gap and high stability for small lattice parameter. It is expected that our studies should be favorable to the further understanding of the hydrogrossular.

\section{Acknowledgement}

This work was supported by a grant from the National Natural Science Foundation of China (Grant No. 51304216).

\section{References}

[1] Cohen-Addad C, Ducros P, Bertaut E F. Etude de la substitution du groupement $\mathrm{SiO}_{4} \mathrm{par}(\mathrm{OH})_{4}$ dans les composés $\mathrm{Al}_{2} \mathrm{Ca}_{3}(\mathrm{OH})_{12}$ et $\mathrm{Al}_{2} \mathrm{Ca}_{3}(\mathrm{SiO} 4)_{2.16}(\mathrm{OH})_{3.36}$ de type grenat [J] Acta Crystallogr. 1967 (23) 220-230.

[2] Lager G A, Armbruster T, Rotella F J. OH substitution in garnets: X-ray and neutron diffraction, infrared, and geometric-modeling studies [J] Am. Mineral. 1989 (74) 840-851.

[3] Weiss R, Grandjean D, Palvin J L. Structure de l'aluminate tricalcique hydrate, $3 \mathrm{CaO} \cdot \mathrm{Al}_{2} \mathrm{O}_{3} \cdot 6 \mathrm{H}_{2} \mathrm{O}[\mathrm{J}]$ Acta Crystallogr. 1964 (17) 1329-1330.

[4] Lager G A. Neutron and X-ray diffraction study of hydrogarnet $\mathrm{Ca}_{2} \mathrm{Al}_{2}\left(\mathrm{O}_{4} \mathrm{H}_{4}\right)_{3}$ [J] Am. Mineral. 1987 (72), $756-765$.

[5] Novak G A, Gibbs G V. The crystal chemistry of the silicate garnets [J] Am. Mineral. 1971 (56), 791-825.

[6] Beltran A, Andres J, Lgualada J A, Carda J. Garnet crystal structures. An ab initio perturbed ion study [J] J. Phys. Chem. 1995 (99) 6493-6501.

[7] Nobes R H, Akhmatskaya E V, Milman V, Winkler B, Pickard C J. Structure and properties of aluminosilicate garnets and katoite: an ab initio study [J] Comput. Mater. Sci. 2000 (17) 141-145.

[8] Sacerdoti M, Passaglia E. The crystal structure of katoite and implications within the hydrogrossular group of minerals [J] Bull. Minéral 1985 (108), 1-8.

[9] Zhang L, Ahsbahs H, Kutoglu A, Geiger C A. Single-crystal hydrostatic compression of synthetic pyrope, almandine, spessartine, grossular and andradite garnets at high pressures [J] Phys. Chem. Miner.1999 (27) 52-58.

[10] Passaglia E, Rinaldi R. Katoite, a new member of the $\mathrm{Ca}_{3} \mathrm{Al}_{2}\left(\mathrm{SiO}_{4}\right)_{3}-\mathrm{Ca}_{3} \mathrm{Al}_{2}(\mathrm{OH})_{12}$ series and a new nomenclature for the hydrogrossular group of minerals [J] Bull. Minéral 1984 (107) 605-618.

[11] O'Neill B, Bass J D, Rossman G R. Elastic properties of hydrogrossular garnet and implications for water in the upper mantle [J] J. Geophys. Res. 1993 (98), 20031 -20037.

[12] Armbruster T, Geiger C A. Andradite crystal chemistry, dynamic X-site disorder and structural 
strain in silicate garnets [J] Eur. J. Mineral. 1993 (5), 59-71.

[13] Geiger C A, Armbruster T. $\mathrm{Mn}_{3} \mathrm{Al}_{2} \mathrm{Si}_{3} \mathrm{O}_{12}$ spessartine and $\mathrm{Ca}_{3} \mathrm{Al}_{2} \mathrm{Si}_{3} \mathrm{O}_{12}$ grossular garnet: Structural dynamic and thermodynamic properties [J] Am. Mineral. 1997 (82),740-747.

[14] Cano N F, Ayta W E F, Watamabe S. Watamabe, Electronic and optical properties of grossular garnet $\left(\mathrm{Ca}_{3} \mathrm{Al}_{2} \mathrm{Si}_{3} \mathrm{O}_{12}\right)$ : An ab initio study [J] Opt. Mater. 2010 (32), 566-569.

[15] Basso R, Della Giusta A, Zefiro L. Crystal structure refinement of plazolite:a highly hydrated natural hydrogrossular [J] N. Jb.Mineral.Mh.1983 251-258.

[16] Armbruster T, Kohler T, Libowitzky E, Friedrich A, Miletich R, Kunz M, Medenbach O, Gutzmer J. Structure, compressibility, hydrogen bonding, and dehydration of the tetragonal $\mathrm{Mn}^{3+}$ hydrogarnet, henritermierite [J] Am. Mineral.2001 (86) 147-158.

[17] Sluiter M H F, Vinograd V, Kawazoe Y. Intermixing tendencies in garnets: Pyrope and grossular [J] Phys. Rev. B 2004 (70) 184120.

[18] Fasoli M, Vedda A, Nikl M, Jiang C, Uberuaga B P, Andersson D A, McClellan K J, Stanek C $\mathrm{R}$. Band-gap engineering for removing shallow traps in rare-earth $\mathrm{Lu}_{3} \mathrm{Al}_{5} \mathrm{O}_{12}$ garnet scintillators using $\mathrm{Ga}^{3+}$ doping [J] Phys. Rev. B, 2011 (84) 081102 (R).

[19] Hansel R A, Allison S W, Walker D G. Temperature-dependent luminescence of $\mathrm{Ce}^{3+}$ in gallium-substituted garnets [J] Appl. Phys. Lett. 2009 (95) 114102.

[20] Monteseguro V, Rodríguez-Hernández P, Lavín V, Manjón F J, Muñoz A. Electronic and elastic properties of yttrium gallium garnet under pressure from ab initio studies [J] J. Appl. Phys. 2013 (113) 183505.

[21] Rák Zs, Ewing R C, Becker U. Electronic structure and thermodynamic stability of uranium-doped yttrium iron garnet [J] J. Phys.: Condens. Matter 2013 (25) 495502.

[22] Kresse G, Hafner J. Ab initio molecular dynamics for liquid metals [J] Phys. Rev. B 1993 (47) 558.

[23] Perdew J P, Wang Y. Accurate and simple analytic representation of the electron-gas correlation energy [J] Phys. Rev. B 1992 (45) 13244.

[24] Monkhorst H J, Pack J D. Special points for Brillouin-zone integrations [J] Phys. Rev. B 1976 (13), 5188. 